\title{
Tuning and Cross Validation of Blomquist-Ladell Model for Pathloss Prediction in the GSM 900 Mhz Frequency Band
}

\author{
Njoku Chukwudi Aloziem, Ozuomba Simeon, Afolayan J. Jimoh \\ Department of Electrical/Electronic and Computer Engineering, University of Uyo, Akwa Ibom, Nigeria \\ Email address: \\ simeonoz@yahoo.com (O. Simeon)
}

\section{To cite this article:}

Njoku Chukwudi Aloziem, Ozuomba Simeon, Afolayan J. Jimoh. Tuning and Cross Validation of Blomquist-Ladell Model for Pathloss Prediction in the GSM 900 Mhz Frequency Band. International Journal of Theoretical and Applied Mathematics. Vol. 3, No. 2, 2017, pp. 94-99. doi: 10.11648/j.ijtam.20170302.18

Received: October 25, 2016; Accepted: December 23, 2016; Published: April 18, 2017

\begin{abstract}
In this paper, Blomquist-Ladell model is tuned and used for the prediction of total pathloss for GSM signal in the $900 \mathrm{MHz}$ band. The model combined free-space loss, excess plane-earth loss and tunable multiple knife-edge diffraction loss to give the total loss. Pathloss data captured from two drive test conducted in Uyo suburban area are used in the study. The first drive test dataset are used to tune the Blomquist-Ladell model, particularly to select the value of the statistical terrain diffraction loss that minimizes the root mean square error (RMSE) of the model prediction. The tuned Blomquist-Ladell model is then cross validated with the second drive test dataset. The results show that the Blomquist-Ladell model performed very well; with the training data (first drive test dataset) the model has RMSE of $2.935598 \mathrm{~dB}$ and Prediction Accuracy of $98.16323 \%$ and in the cross validation data (the second drive test dataset) the model has RMSE of 3.398141dB and Prediction Accuracy of $97.82251 \%$. In both cases, the RMSE is below $3.5 \mathrm{~dB}$ which is below the acceptable maximum value of $7 \mathrm{~dB}$ for such pathloss prediction model.
\end{abstract}

Keywords: Blomquist-Ladell Model, Pathloss, Plane-Earth Loss Model, Cross Validation Test, Diffraction Loss

\section{Introduction}

As radio waves propagates through space their signal strength decreases due to losses that exist in the signal path. The reduction in power density (attenuation) of an electromagnetic wave as it propagates through space is called path loss or path attenuation $[1,2,3]$. Path loss plays vital role to decide the quality of service (QoS) for wireless communication at network planning level. Consequently, wireless network planners find it necessary to determine the extent of the signal loss for a given radio path $[1,3]$.

Path loss may be due to many effects, such as free-space loss, refraction, diffraction, reflection, aperture-medium coupling loss, and absorption. Path loss is also influenced by terrain contours, environment (urban or rural, vegetation and foliage), propagation medium (dry or moist air), the distance between the transmitter and the receiver, and the height and location of antennas [1,2].

In order to predict the path loss that is inherent in a given area, pathloss prediction models are developed. The most common approaches to propagation modeling are empirical models that use measurement data to define a model path loss equation and physical models that use physical radio wave principles such as; free space transmission, reflection or diffraction (Kumar, 2011). However, in practice, experts have noted that the most appropriate path loss model depends on the location of the receiving antenna $[1,3,4]$.

While free space loss is likely to give an accurate estimate of path loss in Location 1, Location 2, a strong line-of-sight is present alone with ground reflections which can significantly influence path loss. In this case, the plane earth loss model appears appropriate. Furthermore, in Location 3, plane earth loss needs to be corrected for significant diffraction losses and foliage loss, caused by trees cutting into the direct line of sight. On the other hand, in Location 4, a simple diffraction model is likely to give an accurate estimate of path loss. In addition, in Location 5, path loss prediction is fairly difficult and unreliable since multiple diffraction are involved. In any case, a typical mobile phone in motion may find itself in a number of those 5 scenarios before. 


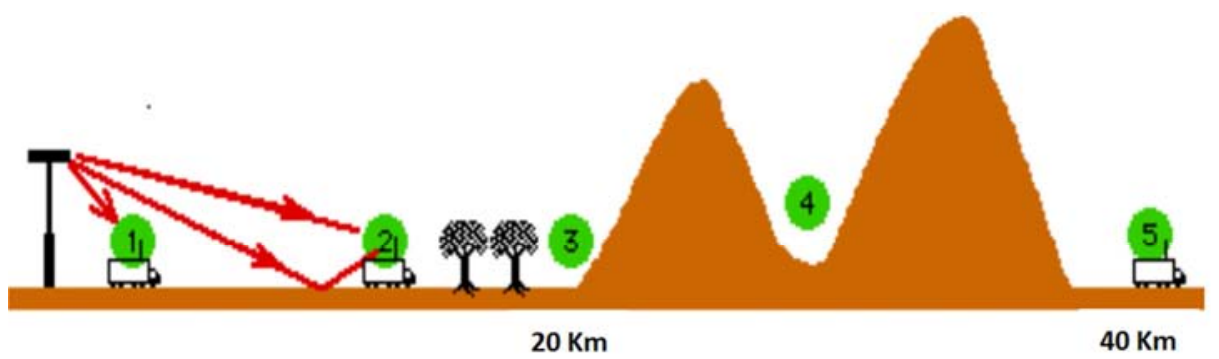

Figure 1. Path loss model depends on the location of the receiving antenna.

In this paper, Blomquist-Ladell model is used for the prediction of total pathloss for GSM signal in the $900 \mathrm{MHz}$ band $[5,6,7,8]$. The model combined free-space loss, excess plane-earth loss and tunable multiple knife-edge diffraction loss to give the total loss. Pathloss data captured from two drive test conducted in Uyo suburban area are used in the study. The first drive test dataset are used to tune the Blomquist-Ladell model, particularly to select the value of the statistical terrain diffraction loss that minimizes the root mean square error (RMSE) of the model prediction. The tuned Blomquist-Ladell model is then cross validated with the second drive test dataset $[9,10,11]$.

\section{Methodology}

Blomquist-Ladell model combined the free-space loss $\left(L_{F S L}\right)$, excess plane-earth loss $\left(L_{E P E L}\right)$, and multiple knife-edge loss $\left(L_{K E D L}\right)$ to give the total loss $\left(L_{T L}\right)$. The excess plane-earth loss is given as $[12,13]$;

$\mathrm{L}_{\mathrm{EPEL}}=10 \log \left(\left|\mathrm{a}_{\mathrm{tx}} \mathrm{a}_{\mathrm{xr}}\right|\right)+\mathrm{Y}$

Where $\mathrm{d}$ is the link distance in meters, $\mathrm{Y}$ is the correction factor,

$$
\begin{gathered}
\mathrm{a}_{\mathrm{tx}}=\frac{4 \pi\left(\mathrm{h}_{\mathrm{tx}}\right)^{2}}{\Lambda \mathrm{d}_{\mathrm{m}}}+\frac{\Lambda\left(\epsilon_{\mathrm{r}}\right)^{2}}{\pi \mathrm{d}\left(\epsilon_{\mathrm{r}}-1\right)} \\
\mathrm{a}_{\mathrm{rx}}=\frac{4 \pi\left(\mathrm{h}_{\mathrm{rx}}\right)^{2}}{\Lambda \mathrm{d}_{\mathrm{m}}}+\frac{\Lambda\left(\epsilon_{\mathrm{r}}\right)^{2}}{\pi \mathrm{d}\left(\epsilon_{\mathrm{r}}-1\right)} \\
\mathrm{Y}=\left\{\begin{array}{c}
-2.8 \mathrm{x} \mathrm{x}<0.53 \\
6.7+10 \log _{10}(\mathrm{x})-10.2 \mathrm{xx} \geq 0.53 \\
\mathrm{x}=\mathrm{d}\left(\frac{2 \pi}{\Lambda}\right)^{1 / 3}(\mathrm{KR})^{-(2 / 3)}
\end{array}\right.
\end{gathered}
$$

Where

$\mathrm{h}_{\mathrm{tx}}$ is the height of transmitter above ground in $\mathrm{m}$ $\mathrm{h}_{\mathrm{rx}}$ is the height of receiver above ground in $\mathrm{m}$

$\mathrm{d}$ is the distance between transmitter and receiver along line of sight path in $\mathrm{km}$

$\mathrm{d}_{\mathrm{m}}$ is the distance between transmitter and receiver along line of sight path in $\mathrm{m}(1000 \mathrm{~d})$

$\mathrm{f}$ is the carrier frequency in $\mathrm{MHz}$

$\lambda$ is the carrier wavelength in $\mathrm{m}$

$\epsilon_{\mathrm{r}}$ is the dielectric constant (relative permittivity) of the ground (Delisle recommends $\epsilon_{\mathrm{r}}=10$ for dry earth [12].

$\mathrm{R}$ is the radius of the earth in $\mathrm{m}\left(\approx 6.371 \times 10^{6}\right)$

$\mathrm{k}$ is the earth radius factor (typically $4 / 3$ ), $\mathrm{c}$ is the speed of light in $\mathrm{m} / \mathrm{s}\left(\approx 299.792 \times 10^{6}\right)$

The free-space loss $\left(\mathrm{L}_{\mathrm{FSL}}\right)$ in $\mathrm{dB}$ is given as;

$$
\mathrm{L}_{\mathrm{FSL}}=32.45+20 \log (\mathrm{f})+20 \log (\mathrm{d})
$$

Where

$\mathrm{f}$ is transmitted frequency in $\mathrm{MHz}$ and $\mathrm{d}$ is path length in $\mathrm{km}$.

Finally, the total loss $\left(\mathrm{L}_{\mathrm{TL}}\right)$ according to Blomquist-Ladell is given as follows:

$L_{T L}=\left\{\begin{array}{c}L_{F S L}+\sqrt[2]{\left(L_{E P E L}\right)^{2}+(\operatorname{Ld}(\Delta \mathrm{h}))^{2}} L_{E P E L} \leq 0 \\ L_{F S L}+\sqrt[2]{\left(L_{E P E L}\right)^{2}+(\operatorname{Ld}(\Delta \mathrm{h}))^{2}} L_{E P E L}>0 \leq \operatorname{Ld}(\Delta \mathrm{h}) \\ L_{F S L}-\sqrt[2]{\left(L_{E P E L}\right)^{2}-(\operatorname{Ld}(\Delta \mathrm{h}))^{2}} L_{E P E L}>0>\operatorname{Ld}(\Delta \mathrm{h})\end{array}\right.$

Where $\operatorname{Ld}(\Delta \mathrm{h})$ is the statistical terrain diffraction loss estimate which describes the "roughness" of the terrain as presented by Delisle, Lefevre, Lecours and Chouinard [12]. A value of $\approx 15$ is considered minimal, $\approx 200$ is used for hilly terrain, and $\approx 400$ for very rugged terrain.. Delisle proposed the method for computing an estimate of additional losses due to terrain [12]. $\mathrm{L}_{\mathrm{FSL}}$ is the basic free-space loss.

\subsection{Drive Test Measurement Campaign and Determination Measured Pathloss}

A handheld Samsung 19500 Galaxy S4 mobile phone was used to take measurement of received signal strength (RSS) from the UMTS $2100 \mathrm{GHz}$ network. The RSS measurements were taken two times along dual lane tarred road in a suburban part of Uyo metropolis. The Samsung 19500 Galaxy S4 has CellMapper Android application installed [14]. The CellMapper captures and displays advanced GSM/CDMA/UMTS/LTE current and neighbouring cells' low level data and can also record and export the data as comma-separated values (CSV) file. Data captured by the CellMapper comprises the current and neighbouring cells RSS in decibels $(\mathrm{dB})$, the current cells cell ID (CID), local area code (LAC). The RSS along with the respective longitudes and latitudes were recorded at each measurement (receiver) point. In addition, the UMTS base station (transmitter) was located, and its longitude and latitude were recorded.

\subsection{Calculation of the Measured Pathloss From the Measured RSS}

After the measurements, Haversine formula was used to determine the distance between the mast (transmitter) and of 
the receiver locations.

The RSS value recorded at each of the receiving point is converted to measured pathloss $\left(P L_{m}(d B)\right.$ by using the formula:

$$
P L_{m}(d B)=(P \mathrm{BTS}+G \mathrm{BTS}+G \mathrm{MS}-L \mathrm{FC}-L \mathrm{AB}-L \mathrm{CF})-
$$

where

$\mathrm{PL}_{\mathrm{m}}(\mathrm{dB})$ is the measured pathloss for each measurement location at a distance $\mathrm{d}(\mathrm{km})$ from the base station.

PBTS $=$ Base transceiver station power $(\mathrm{dBm})$,

GBTS $=$ Base transceiver station antenna gain $(\mathrm{dBi})$,

$\mathrm{GMS}=$ Mobile station antenna gain $(\mathrm{dBi})$,

$\mathrm{LFC}=$ Feeder cable and connector loss $(\mathrm{dB})$,

$\mathrm{LAB}=$ Antenna body loss $(\mathrm{dB})$ and

$\mathrm{LCF}=$ Combiner and filter loss $(\mathrm{dB})$.

The values of these parameters are given by as:

$\mathrm{P}$ BTS $=40 \mathrm{~W}=\left[30+10 \log _{10} 40\right]=46 \mathrm{dBm}$; $\mathrm{GBTS}=18.15 \mathrm{dBi}, \mathrm{GMS}=0 \mathrm{dBi}, \mathrm{LFC}=3 \mathrm{~dB}, \mathrm{LAB}=3 \mathrm{~dB}$, $\mathrm{LCF}=4.7 \mathrm{~dB}$. The measured path loss value in $\mathrm{dB}$ obtained for each of the measurement points is recorded in Table 1 . The receiver locations, distance, RSS, measured path loss and Okumura-Hata model predicted Pathloss are also given in Table 1.

\subsection{Prediction Performance Analysis of the Model}

In order to evaluate the prediction performance of the model, the root mean square error (RMSE), prediction accuracy (PA), the absolute minimum prediction error (AMNPE) and the absolute maximum prediction error (AMXPE) are calculated for the models.

Let $\mathrm{PL}_{(\text {measured)(i) }}$ be the measured path loss $(\mathrm{dB})$, let $\mathrm{PL}_{\text {(predicted)(i) }}$ be the predicted path loss $(\mathrm{dB})$ and let $\overline{P L_{(\text {measured })}}$ be the mean of measured path loss and let $\mathrm{n}$ be the number of measured data points. The RMSE is estimated as:

$$
\operatorname{RMSE}=\sqrt{\left\{\frac{1}{n}\left[\sum_{\mathrm{i}=1}^{\mathrm{i}=\mathrm{n}}\left|\mathrm{PL}_{(\text {measured })(\mathrm{i})}-\mathrm{PL}_{(\text {predicted)(i) }}\right|^{2}\right]\right\}}
$$

Then, the prediction accuracy based on mean absolute percentage error (MAPE) is calculated as:

$$
\begin{gathered}
\text { Prediction Accuracy }= \\
\left\{1-\frac{1}{\mathrm{n}}\left(\sum_{\mathrm{i}=1}^{\mathrm{i}=\mathrm{n}}\left|\frac{\mid \mathrm{PL}_{(\text {measured })(\mathrm{i})}-\mathrm{PL}_{(\text {predicted })(\mathrm{i})}}{\mathrm{PL}_{(\text {measured })(\mathrm{i})}}\right|\right)\right\} \times 100 \%
\end{gathered}
$$

The absolute minimum prediction error (AMNPE) is given as;

$$
\begin{aligned}
& \text { AMNPE }=\operatorname{minimum}\left(\mid P L_{(\text {measured })(i)}-\right. \\
& \left.P L_{(\text {predicted })(i)} \mid\right) \text { for all I }
\end{aligned}
$$

the absolute maximum prediction error (AMXPE) is given as;

$$
\begin{aligned}
& \mathrm{AMXPE}=\operatorname{maximum}\left(\mid P L_{(\text {measured })(i)}-\right. \\
& \left.P L_{(\text {predicted })(i)} \mid\right) \text { for all I }
\end{aligned}
$$

\section{Result}

Two drive tests were conducted. The data captured in the two drive tests are presented in table 1 and table 2 as well as in figure 2 and figure 3.

The dataset of the first drive test is used to train or tune the Blomquist-Ladell model parameters. Specifically, the Delisle statistical terrain diffraction loss estimate $(\operatorname{Ld}(\Delta \mathrm{h})$ is selected by running Microsoft Excel Solver's nonlinear optimization tool on the first drive test data. According to Delisle et al (1985), $\mathrm{Ld}(\Delta \mathrm{h})$ value of 15 is set as the minimum and 400 as the maximum. The Microsoft Excel's Solver nonlinear optimization is run with the condition that $15 \leq \operatorname{Ld}(\Delta \mathrm{h}) \leq$ 400 and the objective is to minimize the root mean square error between the measured pathloss in the first drive test and the Blomquist-Ladell model predicted pathloss. The Microsoft Excel's Solver optimization gave optimal value of the statistical terrain diffraction loss estimate $(\operatorname{Ld}(\Delta \mathrm{h})$ as $35.19764 \mathrm{~dB}$.

Afterwards the tuned Blomquist-Ladell model (with $(\operatorname{Ld}(\Delta \mathrm{h})$ $=35.19764 \mathrm{~dB}$ ) based on the first drive test is cross validated by using the model to predict the pathloss at the same measurement points in the second drive test dataset. The measured and the predicted pathloss for the two drive test datasets are presented in table 3 and table 4 as well as in figure 4 and figure 5. The prediction performance of the Blomquist-Ladell model for the two datasets is shown in table 5 .

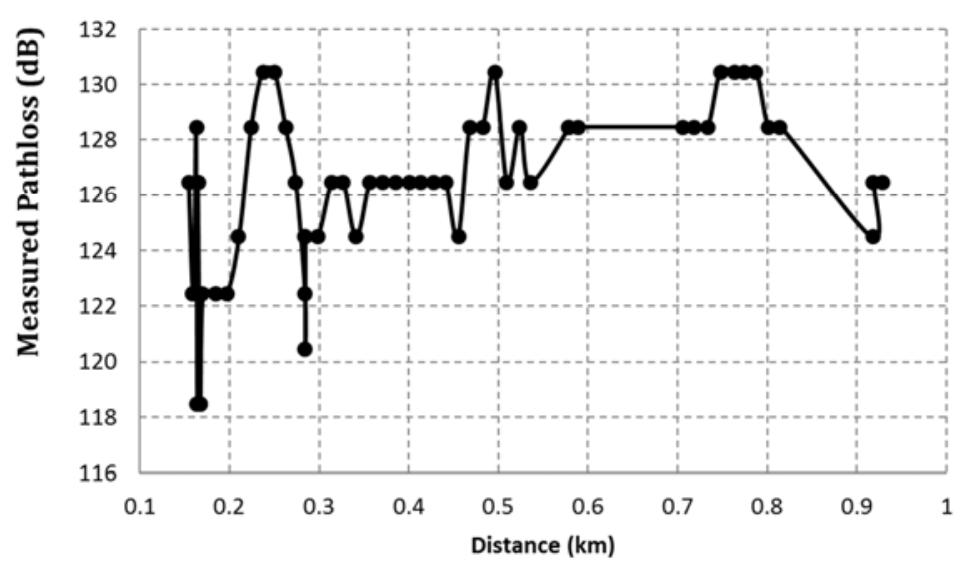

Figure 2. Measured Pathloss (dB) Versus Distance ( $\mathrm{km}$ ) For The First Drive Test Dataset In Table 1. 
Table 1. First drive test dataset that includes Received Signal Strength (RSSI), the measured pathloss and the distance (d) of the measurement points from the transmitter base station.

\begin{tabular}{llllllll}
\hline S/N & $\mathbf{d}(\mathbf{k m})$ & RSSI(dB) & Measured Pathloss $(\mathbf{d B})$ & $\mathbf{S} / \mathbf{N}$ & $\mathbf{d}(\mathbf{k m})$ & RSSI(dB) & Measured Pathloss $(\mathbf{d B})$ \\
\hline 1 & 0.1545 & -73 & 126.5 & 29 & 0.385 & -73 & 126.5 \\
3 & 0.1626 & -75 & 128.5 & 31 & 0.4131 & -73 & 126.5 \\
5 & 0.163 & -73 & 126.5 & 33 & 0.4412 & -73 & 126.5 \\
7 & 0.1645 & -73 & 126.5 & 35 & 0.468 & -75 & 128.5 \\
9 & 0.1675 & -65 & 118.5 & 37 & 0.4955 & -77 & 130.5 \\
11 & 0.1836 & -69 & 122.5 & 39 & 0.524 & -75 & 128.5 \\
13 & 0.2106 & -71 & 124.5 & 41 & 0.5792 & -75 & 128.5 \\
15 & 0.237 & -77 & 130.5 & 43 & 0.5896 & -75 & 128.5 \\
17 & 0.2624 & -75 & 128.5 & 45 & 0.7196 & -75 & 128.5 \\
19 & 0.2843 & -69 & 122.5 & 47 & 0.7474 & -77 & 130.5 \\
21 & 0.2848 & -71 & 124.5 & 49 & 0.7742 & -77 & 130.5 \\
23 & 0.2984 & -71 & 124.5 & 51 & 0.8009 & -75 & 128.5 \\
25 & 0.3269 & -73 & 126.5 & 53 & 0.917 & -71 & 124.5 \\
27 & 0.3568 & -73 & 126.5 & 55 & 0.9285 & -73 & 126.5 \\
\hline
\end{tabular}

Table 2. The Cross Validation Data (The Second drive test dataset) that includes measured Received Signal Strength (RSSI), the measured pathloss and the distance (d) of the measurement points from the transmitter base station.

\begin{tabular}{llllllll}
\hline S/N & $\mathbf{d}(\mathbf{k m})$ & RSSI $(\mathbf{d B})$ & Measured Pathloss $(\mathbf{d B})$ & $\mathbf{S} / \mathbf{N}$ & $\mathbf{d}(\mathbf{k m})$ & RSSI $(\mathbf{d B})$ & Measured Pathloss $(\mathbf{d B})$ \\
\hline 1 & 0.1525 & -73 & 126.5 & 29 & 0.3781 & -75 & 128.5 \\
3 & 0.1625 & -75 & 128.5 & 31 & 0.4061 & -73 & 126.5 \\
5 & 0.1638 & -73 & 126.5 & 33 & 0.4341 & -73 & 126.5 \\
7 & 0.1641 & -65 & 118.5 & 35 & 0.4627 & -71 & 124.5 \\
9 & 0.1671 & -65 & 118.5 & 37 & 0.4889 & -75 & 128.5 \\
11 & 0.1776 & -69 & 122.5 & 39 & 0.5163 & -73 & 126.5 \\
13 & 0.2044 & -71 & 124.5 & 41 & 0.5416 & -73 & 126.5 \\
15 & 0.2306 & -75 & 128.5 & 43 & 0.5842 & -77 & 130.5 \\
17 & 0.2563 & -77 & 130.5 & 45 & 0.7279 & -75 & 128.5 \\
19 & 0.2794 & -71 & 124.5 & 47 & 0.7544 & -77 & 130.5 \\
21 & 0.2844 & -67 & 120.5 & 49 & 0.7808 & -77 & 130.5 \\
23 & 0.2899 & -71 & 124.5 & 51 & 0.8091 & -75 & 128.5 \\
25 & 0.3208 & -73 & 126.5 & 53 & 0.8545 & -69 & 122.5 \\
27 & 0.3494 & -73 & 126.5 & 55 & 0.9257 & -73 & 126.5 \\
\hline
\end{tabular}

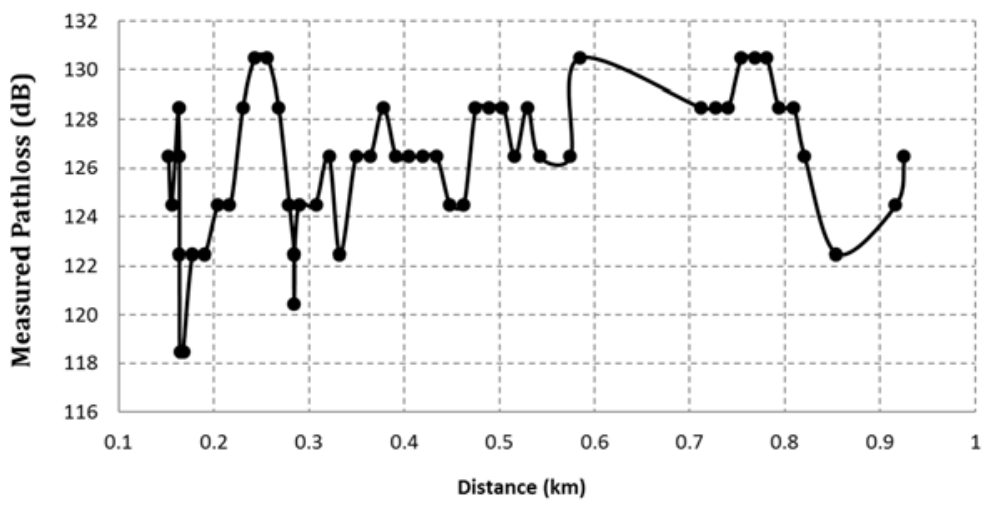

Figure 3. Measured Pathloss (dB) Versus Distance (km) for the Cross Validation Data (the Second Drive Test Dataset) in Table 2.

Table 3. Measured Pathloss (dB) and Predicted Pathloss Versus Distance ( $\mathrm{km}$ ) Based On The First Drive Test Dataset in Table 1.

\begin{tabular}{llllllll}
\hline S/N & $\mathbf{d}(\mathbf{k m})$ & Measured Pathloss $(\mathbf{d B})$ & Predicted Pathloss $(\mathbf{d B})$ & $\mathbf{S} / \mathbf{N}$ & $\mathbf{d}(\mathbf{k m})$ & Measured Pathloss $(\mathbf{d B})$ & Predicted Pathloss $(\mathbf{d B})$ \\
\hline 1 & 0.1545 & 126.45 & 125.1 & 29 & 0.385 & 126.45 & 127.7 \\
3 & 0.1626 & 128.45 & 125.2 & 31 & 0.4131 & 126.45 & 128 \\
5 & 0.163 & 126.45 & 125.2 & 33 & 0.4412 & 126.45 & 128.2 \\
7 & 0.1645 & 126.45 & 125.2 & 35 & 0.468 & 128.45 & 128.4 \\
9 & 0.1675 & 118.45 & 125.3 & 37 & 0.4955 & 130.45 & 128.6 \\
11 & 0.1836 & 122.45 & 125.5 & 39 & 0.524 & 128.45 & 128.8 \\
13 & 0.2106 & 124.45 & 125.9 & 41 & 0.5792 & 128.45 & 129.2 \\
15 & 0.237 & 130.45 & 126.2 & 43 & 0.5896 & 128.45 & 129.3 \\
17 & 0.2624 & 128.45 & 126.5 & 45 & 0.7196 & 128.45 & 130.1 \\
19 & 0.2843 & 122.45 & 126.8 & 47 & 0.7474 & 130.45 & 130.2 \\
21 & 0.2848 & 124.45 & 126.8 & 49 & 0.7742 & 130.45 & 130.4 \\
\hline
\end{tabular}




\begin{tabular}{llllllll}
\hline S/N & $\mathbf{d}(\mathbf{k m})$ & Measured Pathloss (dB) & Predicted Pathloss $\mathbf{( d B})$ & S/N & $\mathbf{d}(\mathbf{k m})$ & Measured Pathloss (dB) & Predicted Pathloss (dB) \\
\hline 23 & 0.2984 & 124.45 & 126.9 & 51 & 0.8009 & 128.45 & 130.5 \\
25 & 0.3269 & 126.45 & 127.2 & 53 & 0.917 & 124.45 & 131.1 \\
27 & 0.3568 & 126.45 & 127.5 & 55 & 0.9285 & 126.45 & 131.2 \\
\hline
\end{tabular}

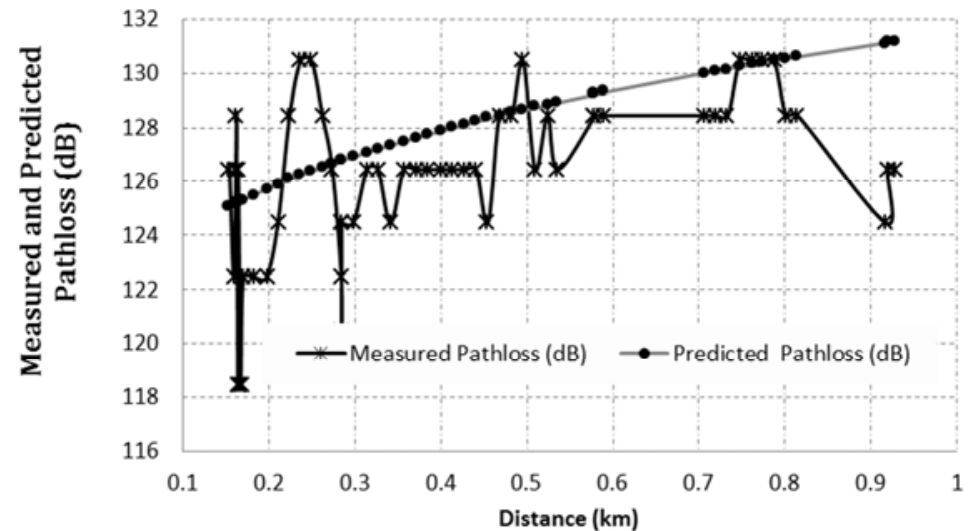

Figure 4. Measured Pathloss (dB) and Predicted Pathloss Versus Distance (km) Based on the First Drive Test Dataset in Table 1 and Table 3.

Table 4. Measured Pathloss (dB) and Predicted Pathloss Versus Distance ( $\mathrm{km}$ ) Based on the Cross Validation Data (the Second Drive Test Dataset) in Table 2.

\begin{tabular}{llllllll}
\hline $\mathbf{S} / \mathbf{N}$ & $\mathbf{d}(\mathbf{k m})$ & Measured Pathloss $(\mathbf{d B})$ & Predicted Pathloss $\mathbf{( d B})$ & $\mathbf{S} / \mathbf{N}$ & $\mathbf{d} \mathbf{( k m )}$ & Measured Pathloss $(\mathbf{d B})$ & Predicted Pathloss $(\mathbf{d B})$ \\
\hline 1 & 0.1525 & 126.45 & 125.03 & 29 & 0.3781 & 128.45 & 127.69 \\
3 & 0.1625 & 128.45 & 125.19 & 31 & 0.4061 & 126.45 & 127.93 \\
5 & 0.1638 & 126.45 & 125.21 & 33 & 0.4341 & 126.45 & 128.16 \\
7 & 0.1641 & 118.45 & 125.22 & 35 & 0.4627 & 124.45 & 128.39 \\
9 & 0.1671 & 118.45 & 125.26 & 37 & 0.4889 & 128.45 & 128.58 \\
11 & 0.1776 & 122.45 & 125.42 & 39 & 0.5163 & 126.45 & 128.78 \\
13 & 0.2044 & 124.45 & 125.81 & 41 & 0.5416 & 126.45 & 128.96 \\
15 & 0.2306 & 128.45 & 126.15 & 43 & 0.5842 & 130.45 & 130.13 \\
17 & 0.2563 & 130.45 & 126.46 & 45 & 0.7279 & 128.45 & 130.28 \\
19 & 0.2794 & 124.45 & 126.72 & 47 & 0.7544 & 130.45 & 130.42 \\
21 & 0.2844 & 120.45 & 126.77 & 49 & 0.7808 & 130.45 & 130.57 \\
23 & 0.2899 & 124.45 & 126.83 & 51 & 0.8091 & 128.45 & 130.81 \\
25 & 0.3208 & 126.45 & 127.15 & 53 & 0.8545 & 122.45 & 131.16 \\
27 & 0.3494 & 126.45 & 127.42 & 55 & 0.9257 & 126.45 & \\
\hline
\end{tabular}

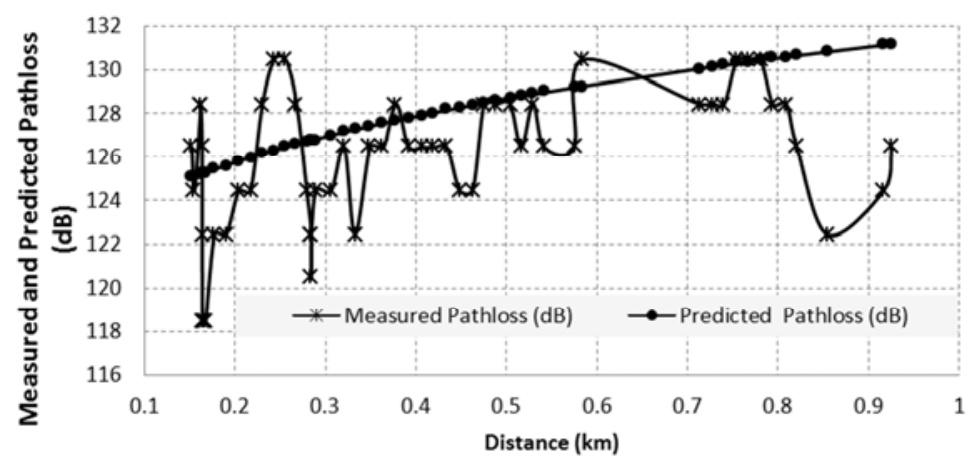

Figure 5. Measured Pathloss (dB) and Predicted Pathloss Versus Distance ( $\mathrm{km}$ ) Based on the Cross Validation Data (The Second Drive Test Dataset) in Table 2 and Table 4.

Table 5. Performance of the Blomquist-Ladell model when applied to the training data (the first drive test dataset)and when applied to the cross validation data (the second drive test dataset).

\begin{tabular}{lll}
\hline Performance Parameter & $\begin{array}{l}\text { Performance of the prediction model } \\
\text { based on the first drive test dataset in } \\
\text { Table 1 and Table 3 }\end{array}$ & $\begin{array}{l}\text { Performance of the prediction model based on the } \\
\text { cross validation data (the second drive test } \\
\text { dataset ) in Table 2 and Table 4 }\end{array}$ \\
\hline Statistical terrain diffraction loss estimate $(\mathrm{Ld}(\Delta \mathrm{h})$ in $\mathrm{dB}$ & 35.19764 & 35.19764 \\
RMSE & 2.935598 & 3.398141 \\
Prediction Accuracy (\%) & 98.16323 & 97.82251 \\
Maximum Prediction Error (\%) & 5.756943 & 6.826954 \\
Minimum Prediction Error (\%) & 0.006765 & 0.020969 \\
\hline
\end{tabular}


In published literatures, RMSE value that is less or equal to $6 \mathrm{~dB}$ is acceptable for pathloss models. Table 5 shows that the Blomquist-Ladell model performed very well in both the training data (first drive test dataset in Table 1 and Table 3) and in the cross validation data (the second drive test dataset) in Table 2 and Table 4. In both cases, the RMSE is below 3.5 dB.

\section{Conclusion}

Pathloss prediction using Blomquist-Ladell model is presented for GSM network in the $900 \mathrm{MHz}$ band. The Blomquist-Ladell model which is a semi empirical model gave very good prediction for the study area and the frequency band. Cross validation result also shows that the model gives good result when applied to other set of data captured around the study area. The key feature that makes the Blomquist-Ladell model useful for practical applications is that it incorporates the free space and the plane earth (reflection) model along with diffraction loss. It also has a tunable diffraction parameter that can be used to make the model prediction suitable for different environment.

\section{References}

[1] Gupta S. (2013) Comparative Path Loss Analysis Of Okumura And COST 231 Models For Wireless Mobile Communication Using MATLAB Simulation. International Journal of Engineering Research \& Technology (IJERT) Vol. 2 Issue 3, March - 2013.

[2] Kumar, K. A. M. (2011). Significance of Empirical and Physical Propagation Models to Calculate the Excess Path Loss. Journal of Engineering Research and Studies, India.

[3] Sharma, D., \& Singh, R. K. (2010). The effect of path loss on Qos at NPL. International Journal of Engineering Science and Technology, 1 (2), 3018-3023.
[4] Misra, I. S. (2013). Wireless Communications and Networks: $3 G$ and Beyond. McGraw Hill Education (India) Pvt Ltd.

[5] Rao, T. R., Rao, S. V. B., Prasad, M. V. S. N., Sain, M., Iqbal, A., \& Lakshmi, D. R. (2000). Mobile radio propagation path loss studies at VHF/UHF bands in Southern India. IEEE transactions on Broadcasting, 46 (2), 158-164.

[6] Rao, T. R., Rao, S. V. B., Prasad, M. V. S. N., \& Sarkar, S. K. (1999). Single Knife edge diffraction propagation studies over a hilly terrain. IEEE transactions on broadcasting, 45 (1), 20-29.

[7] Phillips, C., Raynel, S., Curtis, J., Bartels, S., Sicker, D., Grunwald, D., \& McGregor, T. (2011, March). The efficacy of path loss models for fixed rural wireless links. In International Conference on Passive and Active Network Measurement (pp. 42-51). Springer Berlin Heidelberg.

[8] Phillips, C., Sicker, D., \& Grunwald, D. (2013). A survey of wireless path loss prediction and coverage mapping methods. IEEE Communications Surveys \& Tutorials, 15 (1), 255-270.

[9] Hornung, R., Bernau, C., Truntzer, C., Stadler, T., \& Boulesteix, A. L. (2014). Full versus incomplete cross-validation: measuring the impact of imperfect separation between training and test sets in prediction error estimation.

[10] Arlot, S., \& Celisse, A. (2010). A survey of cross-validation procedures for model selection. Statistics surveys, 4, 40-79.

[11] Cawley, G. C. (2006, July). Leave-one-out cross-validation based model selection criteria for weighted LS-SVMs. In The 2006 IEEE International Joint Conference on Neural Network Proceedings (pp. 1661-1668). IEEE.

[12] Delisle, G. Y., Lefevre, J. P., Lecours, M., \& Chouinard, J. Y. (1985). Propagation loss prediction: A comparative study with application to the mobile radio channel. IEEE Transactions on Vehicular Technology, 34 (2), 86-96.

[13] Phillips, C. T. (2012). Geostatistical techniques for practical wireless network coverage mapping.

[14] Tocado, F. J. R., Zayas, A. D., \& Gómez, P. M. (2014). Characterizing traffic performance in cellular networks. IEEE Internet Computing, 18 (1), 12-19. 